\title{
Nueva imagen y organización editorial de la Revista de la Sociedad Española del Dolor
}

En este primer número del 2019, la RESED, la Revista de la Sociedad Española del Dolor, cambia el formato y diseño de la portada y de los artículos, dentro de la estrategia de adaptación, actualización y mejoras en la calidad global editorial. Asimismo, parte de la estructura y composición del Comité Editorial ha cambiado, con la creación de la figura del Editor Ajunto, que recae en la persona de la Dra. Concepción Pérez, y el cargo de Editores Asociados con el nombramiento de responsables de 6 áreas científicas que recaen en el Profesor Enrique J. Cobos (Ciencias Básicas), el Profesor Carlos Goicoechea (Farmacología), la Profesora Inmaculada Failde (Epidemiología), la Dra. Luz Cánovas (Clínica), el Dr. Alejandro Ortega (Imagen) y el Dr. David Abejón (Intervencionismo).

Esta nueva composición y estructura editorial crea un equipo de trabajo que aúna experiencia, competencia, ideas, ilusión y motivación para potenciar la $R E S E D$, y que comparte la misión y visión de intentar alcanzar los objetivos de visibilidad y calidad científica y editorial deseables. La exigencia para alcanzar las metas por parte de los organismos y Agencias Nacionales e Internacionales de evaluación e indexación son elevadas y requieren tiempo y dedicación, así como una adaptación de todos los procesos editoriales. Asimismo, es esencial la contribución científica de los revisores, de los autores y de los lectores, que esperamos sea creciente, ofreciéndoles un espacio de divulgación y creación científica en la Medicina del Dolor en todas sus dimensiones. La RESED es una de las revistas más importantes de habla hispana en esta área de conocimiento, y abierta también al mundo anglosajón, recibiendo y publicando artículos en inglés. Por ello, tenemos el interés de que RESED sea un lugar de encuentro y acogida, confortable y amigable, y que potencie los intereses y el prestigio de todos los quieran contribuir con su participación y aportaciones.

Por último, hemos incluido una nueva sección, a cargo de los Editores Asociados, denominada Avances en dolor, que incluye comentarios sobre artículos actuales de especial relevancia e interés científicos, con el fin de aumentar el valor y el conocimiento en el campo del dolor.

Una parte importante del impacto de RESED como órgano de expresión científica de la SED depende de la calidad de sus contenidos y de la gestión editorial en proceso de cambios, pero también de la proyección, de la imagen y de la Difusión que pueda tener y se pueda implementar. En este sentido, el Comité editorial y la propia Junta de la Sociedad Española del Dolor hemos promovido un cambio de imagen que sea atractivo y que ayude a transmitir el compromiso con los valores éticos y científicos, formativos, divulgativos y sociales de la SED y de la Medicina del Dolor.

Deseamos y esperamos que una parte de los avances en la Medicina del Dolor sean una contribución de la RESED y de todos los que buscan o se reflejan en ella. 